\title{
ANALISIS STRAIN HARDENING DENGAN VARIASI MEDIA QUENCHING DALAM MENINGKATKAN MUTU PRODUK PENGRAJIN PANDAI BESI SUNGAI PUAR, KAB. AGAM SUMATERA BARAT
}

\author{
ARMILA \\ Teknik Mesin, Fakultas Teknik, Universitas Muhammadiyah Sumatera Barat \\ Kimmylala74@gmail.com
}

\begin{abstract}
Abstrak: Pandai besi Sungai Puar mengalami penurunan jumlah pengrajin yang disebabkan oleh kurang baiknya mutu produk dan adanya pasar global dimana produk China yang jauh lebih bagus dan murah. Kurangnya pengetahuan tentang bagaimana meningkatkan kekerasan yang menyebabkan kemunduran sentra industri ini. Peningkatan mutu produk hanya dengan perlakuan panas yang sudah dilakukan secara turun temurun. Akan tetapi proses perlakuan panas tersebut belum tepat. Perlakuan panas dengan pemanasan material logam sampai temperatur austenit $(\gamma)$ kemudian dilanjutkan dengan penahanan temperatur sekitar 30 menit dan kemudian didinginkan secara cepat. Pendinginan cepat dapat dilakukan dalam media pendingin yang bervariasi. Dari hasil uji keras menggunakan Mikro Vickers pendinginan dengan air sumur didapat kekerasan $652 \mathrm{VHN}$, dengan air garam 869.66 VHN, Oli 605,52. Angka kekerasan dengan media air garam paling bagus akan tetapi angka kekerasan juga harus diteliti lebih lanjut agar kekerasan yang didapat seiring dengan ketahanan terhadap korosi, karena viskositas air garam yang rendah dengan densitas yang tinggi menyebabkan laju pendinginan lebih cepat sehingga kekerasan yang didapat lebih tinggi. Pendinginan cepat dimaksudkan agar mekanisme terbentuknya fasa martensit lebih besar sehingga angka kekeras

Kata Kunci: Pandai Besi, Fasa Austenit, Fasa Martensit, Pendinginan Cepat, Mikro Vickers
\end{abstract}

\begin{abstract}
Abstrac: Blacksmith at Sungai Puar Region was decreasing caused by low quality and global marked. China's product more cheaper $\mathrm{n}$ hight quality. Heat Treatment process not worked as metallurgy rules, its still in traditional working. Mechanical properties such, toughness, strength, hardness strength can easily be modified by heat treating for medium carbon steel, were subjected to various forms of heat treatment processes like hardening and tempering. Samples were austenitised at 850$900^{\circ} \mathrm{C}$ followed by holding times and finally they were quenched in salt water, oil, and fresh water. The specimen with the highest hardness was found in samples quenched in salt water, they are $869,66 \mathrm{VHN}$ in salt water, 605.52 in oil, and $652 \mathrm{VHN}$ in fresh water. Its because salt water have hight density n low viscosity were sample cooled fast, and martensite structure obtained, and hardness increased. Micro Vickers hardness used for samples. Behavior of hight hardness quenched in salt water must be learning more, to measure corrosion rate and toughness.
\end{abstract}

Key Word: Blacksmith, Micro Vickers, Quenching, Martensite, Austenite

\section{PENDAHULUAN \\ Latar Belakang}

Penelitian terdahulu penulis melakukan penelitian tentang berkurangnya jumlah pengrajin pandai besi di daerah Sungai Puar, dimana daerah ini merupakan sentra pertanian dan perkebunan yang subur yang membuat sendiri alat-alat pertanian berupa cangkul, sabit, garpu dan bajak, selain itu juga membuat alat-alat kebutuhan rumah tangga seperti pisau, golok dll. Dimana produksinya selain digunakan untuk kebutuhan sendiri juga dipasok keseluruh wilayah pertanian, perkebunan di Sumatera Barat. Seiring berkembangnya pasar bebas dimana produk China sebagai salah satu penyebab kemunduran sentra industri ini. jika diteliti lebih dalam ternyata tidak hanya produk China yang jadi penyebab akan tetapi kwalitas produk pandai besi tidak sesuai dengan yang diharapkan petani dan masyarakat, dimana mereka menginginkan produk yang kuat, tangguh dan tahan karat.

Penelitian terdahulu penulis mengamati secara seksama urutan proses produksi, dimana ditemukan beberapa kesalahan dalam proses produksi, mulai dari pengaturan temperatur, proses tempa (forging) dan proses hardening (sepuh), yang bertujuan untuk menambah kekuatan pada material dengan mengubah struktur mikro dengan metoda "quenching"/pendinginan cepat. 
Kesalahan dari metoda quenching ini yang ingin dibahas lebih lanjut dengan memvariasikan media quenching agar kekerasan produk dapat ditingkatkan.

\section{Tujuan Kegiatan}

Adapun tujuan dari kegiatan ini adalah untuk meneliti angka kekerasan produk pandai besi dengan menggunakan media pendingin yang berbeda. Dimana selama turun temurun pengrajin pandai besi hanya melakukan proses strain hardening hanya menggunakan media air saja.

Pada dasarnya media air sebagai media pendingin dalam proses strain hardening itu sudah tepat, hanya saja pengaturan temperatur pemanasan untuk proses hardening ini yang sering kurang diperhatikan. Pengrajin hanya menilai temperatur hardening hanya berdasarkan visual warna baja saja, tidak dilakukan proses penahanan temperatur sebagaimana mestinya, dimana penahanan temperatur merupakan kunci dari keberhasilan proses strain hardening.

Dalam kegiatan ini penulis mencoba melakukan proses hardening dengan memberikan variasi pada media pendingin berupa, air biasa, air garam, oli dan udara. Material yang dijadikan sampel pengujian berupa sabit.

\section{TINJAUAN PUSTAKA}

\section{Spesifikasi Material}

Pengrajin pandai besi Sungai Puar umumnya menggunakan material bekas dari per/pegas daun mobil dan truk. Pegas daun merupakan baja karbon sedang dengan kadar karbon 0,5-0,6\% C, material uji yang dipakai adalah baja karbon 0,63\% dan Baja Karbon $0,54 \%$ C. Baja karbon ini mampu untuk dilakukan proses perlakukan panas terutama proses strain hardening yang diikuti dengan proses quenching.

Hasil proses spektrometri material uji seperti table berikut:

\begin{tabular}{|c|c|c|}
\hline \multirow{2}{*}{ Unsur } & \multicolumn{2}{|c|}{ Pegas Daun } \\
\cline { 2 - 3 } & A & B \\
\hline $\mathrm{C}$ & 0.633 & 0.546 \\
\hline $\mathrm{Si}$ & 0.302 & 0.307 \\
\hline $\mathrm{Mn}$ & 0.781 & 0.776 \\
\hline $\mathrm{P}$ & 0.002 & 0.0024 \\
\hline
\end{tabular}

\begin{tabular}{|c|c|c|}
\hline $\mathrm{S}$ & 0.176 & 0.0184 \\
\hline $\mathrm{Cr}$ & 0.768 & 0.646 \\
\hline $\mathrm{Mo}$ & 0.0289 & 0.0297 \\
\hline $\mathrm{Ni}$ & 0.0159 & 0.0176 \\
\hline $\mathrm{Al}$ & 0.0087 & 0.0097 \\
\hline $\mathrm{Cu}$ & 0.0157 & 0.0154 \\
\hline $\mathrm{V}$ & 0.0061 & 0.0060 \\
\hline $\mathrm{W}$ & 0.0029 & 0.0032 \\
\hline $\mathrm{Fe}$ & 95.9 & 95.8 \\
\hline
\end{tabular}

\section{Prinsip Kerja Strain Hardening}

Stain hardening merupakan salah satu proses perlakuan panas yang mampu meningkatkan kekerasan baja hasil proses pembentukan logam.

Material uji adalah baja karbon sedang, dimana baja ini merupakan material yang mempunyai hardenability yang baik yang dapat diukur dengan proses Jominy dan grossman.

Maksud dari perlakuan panas dalam penelitian ini adalah untuk meningkatkan strain hardening produk pandai besi pengrajin Nagari Sungai Puar. Dimana konsepnya hanya memadukan proses pemanasan dan pendinginan secara cepat, guna untuk mendapat sifat-sifat tertentu.

Dalam proses ini produk hasil tempa dipanaskan sampai temperatur austenit $(\gamma)$ kemudian didinginkan secara cepat kedalam air. Agar terbentuk fasa martensit yang membuat material bersifat keras. Fasa martensit yang terbentuk dapat dijelaskan dengan diagram fasa $\mathrm{Fe}-\mathrm{Fe} 3 \mathrm{C}$ seperti gambar berikut:

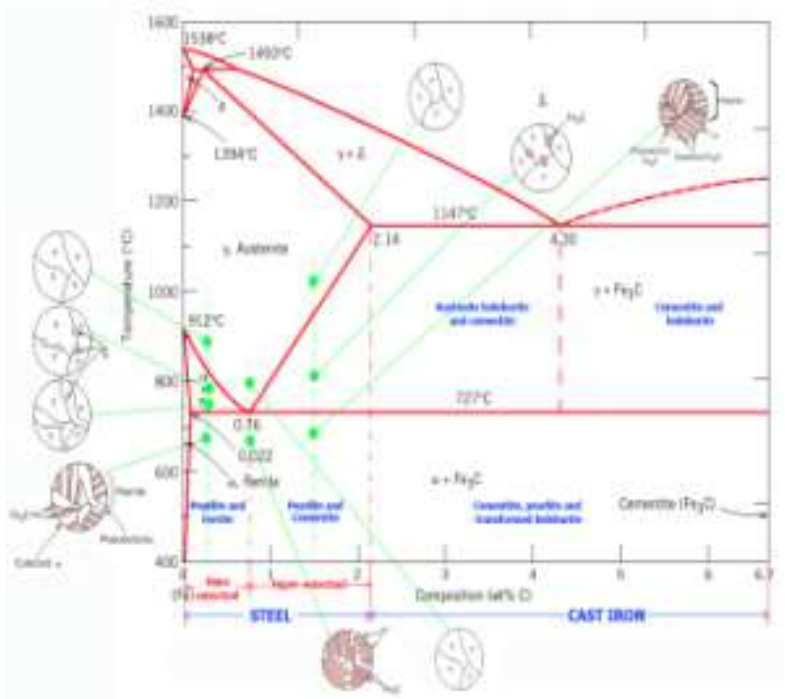

Gambar 2.1 Diagram Fasa $\mathrm{Fe}-\mathrm{Fe}_{3} \mathrm{C}$ 
Pelaksanaan proses Strain Hardening dapat dijelaskan sebagai berikut:

1. Preheating (pemanasan kembali).

Proses preheating/pemanasan ulang adalah proses pemanasan material hasil tempa, dimana material dipanaskan kembali sampai temperatur austenite $(\gamma)$ atau temperatur gamma, karena pemanasan sampai temperatur ini merupakan sebuah rule/aturan dalam proses pengerjaan panas. Dimana dengan pemanasan sampai temperatur austenite fasa bersifat stabil dan mampu untuk menghasilkan struktur martensit yang diinginkan. Temperatur austenite jika dianalogikan sama dengan kisaran $850-900^{\circ} \mathrm{C}$, atau kalau pengrajin melihat visual warna jingga terang.

2. Penahanan Temperatur (Holding Time).

Penahanan temperatur ini dimaksudkan untuk menyeragamkan temperatur sehingga fasa austenite yang diinginkan bersifat homogen dan stabil.

Lama penahanan temperatur ini tergantung dari kadar karbon material.

Biasanya untuk baja karbon sedang holding time yang dibutuhkan antara 20-30 menit, akan tetapi para pengrajin tidak/kurang memahami hal ini, dimana mereka tidak melakukan proses penahanan temperatur produk sehingga produk yang dihasilkan bersifat getas.

3. Pendinginan Cepat (Quenching).

Dalam proses stain hardening ini pendinginan yang dilakukan bersifat cepat dengan menggunakan media air. dimana tujuan pendinginan secara cepat adalah untuk mendapatkan fasa martensit yang akan membuat material menjadi kuat dan keras.

\section{Media Pendingin}

Dalam proses pendinginan/quenching kita bisa memakai berbagai macam media pendingin tergantung dari sifat material yang kita inginkan. Dalam hal ini beberapa penelitian telah mencoba mencari variasi dengan media antara lain:

1. Air

Media air adalah media yang sangat banyak digunakan karena media ini akan menghasilkan material dengan strain hardening yang tinggi, karena pendinginan yang cepat dapat merubah fasa autenit menjadi martensit. Saat ini peneliti lebih mencoba mencari terobosan dengan menambahkan garam pada media air ini, karena dari penambahan garam pendinginan temperatur akan lebih cepat turun dibanding dengan pendinginan air biasa, sehingga kekerasan yang didapat lebih tinggi.

2. Oli atau Minyak

Media oli atau minyak juga banyak digunakan, media ini akan lebih lambat menghasilkan penurunan temperatur, akan tetapi kekerasan yang didapat tetap tinggi dan meghasilkan lapisan karbon pada permukaan logam.

3. Udara

Pendinginan dengan media udara merupakan pendinginan lambat atau biasa disebut (normalizing)/normalisasi.

Pendinginan ini bertujuan untuk mendapatkan kekerasan dengan proses pendingian lambat sehingga memberikan ruang pada logam untuk merubah struktur mikro logam dengan metoda pertumbuhan butir atau rekristalisasi.

Proses pendinginan dan fasa yang terbentuk dapat dijelaskan dengan menggunakan diagram CCT dan TTT sebagai berikut:

\section{Time-Temperature Transformation Diagram}

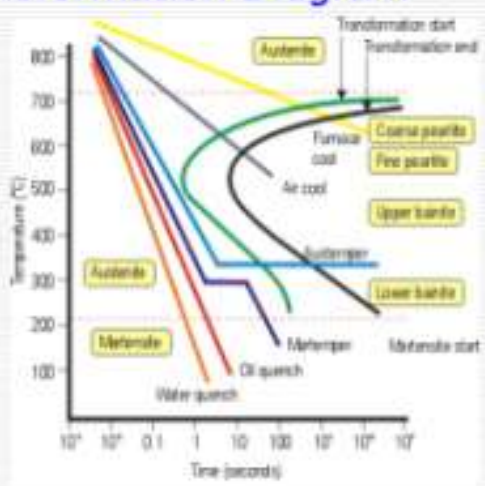

Gambar 2.2 Diagram TTT secara umum

Perubahan Fasa yang terjadi selama proses pendinginan dapat dijelaskan dengan digram TTT berikut ini: 


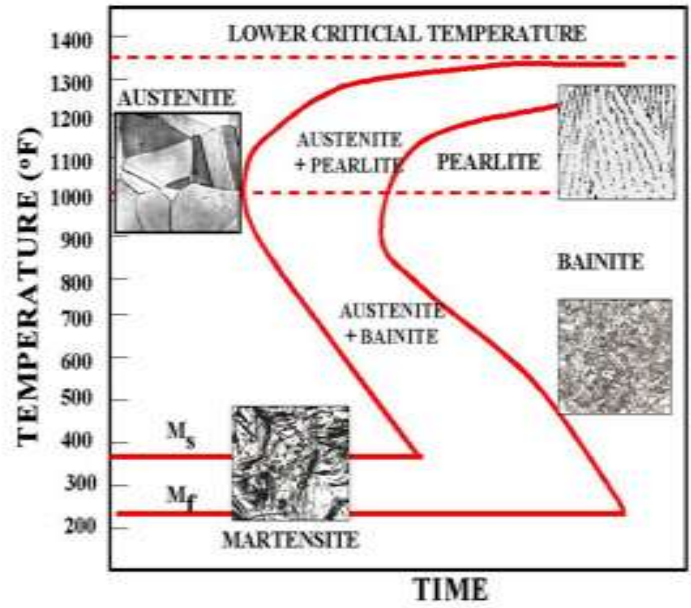

Gambar 2.3 Diagram TTT dalam perubahan fasa

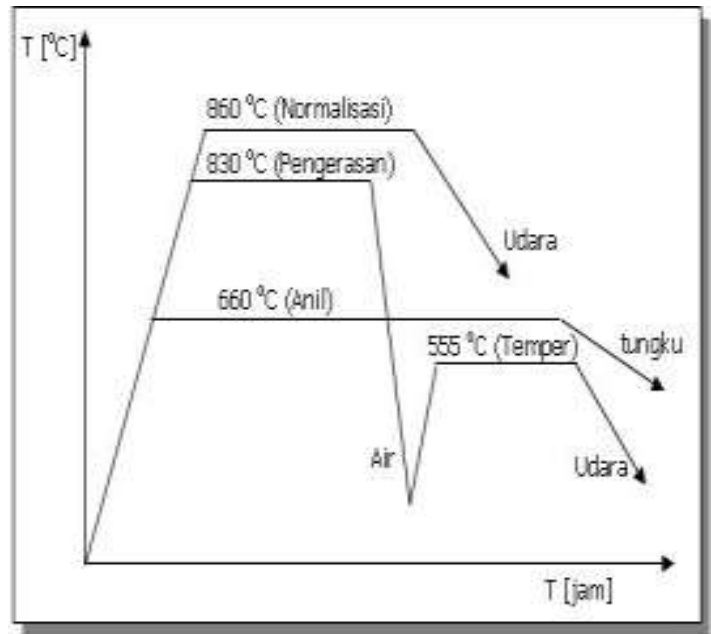

Gambar 2.4 Kurva Penahanan Temperatur holding time

\section{Pengujian Material}

Dalam penelitian ini angka kekerasan di uji dengan metoda Mikro Vickers. Metoda mikro Vickers merupakan pengujian kekerasan tanpa merusak benda uji, hasilnya lebih akurat karena jejak indentor dalam bentuk piramida dengan alas segi empat besar sudut $136^{\circ}$.
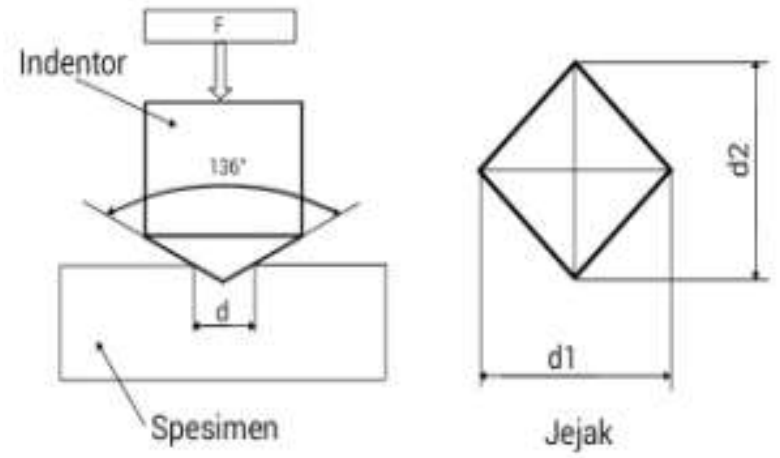

Gambar 2.5 Mekanisme pengujian Vickers

$$
\begin{gathered}
A=4 \times \frac{1}{2} \mathrm{~d} \sqrt{2} \times \frac{1}{2}\left(\frac{\mathrm{d} \sqrt{2}}{4 \sin \frac{\alpha}{2}}\right) \\
A=\frac{d^{2}}{2 \sin \frac{136}{2}}
\end{gathered}
$$

Dimana angka kekerasan diperoleh dengan rumus sebagai berikut:

$$
\begin{aligned}
& H V=\frac{P / d^{\wedge} 2}{2 \sin \frac{136^{0}}{2}} \\
& \quad H V=1.854 \frac{P}{d^{2}}
\end{aligned}
$$

Proses pengujian mikro Vickers dapat terlihat pada mesin uji berikut ini:

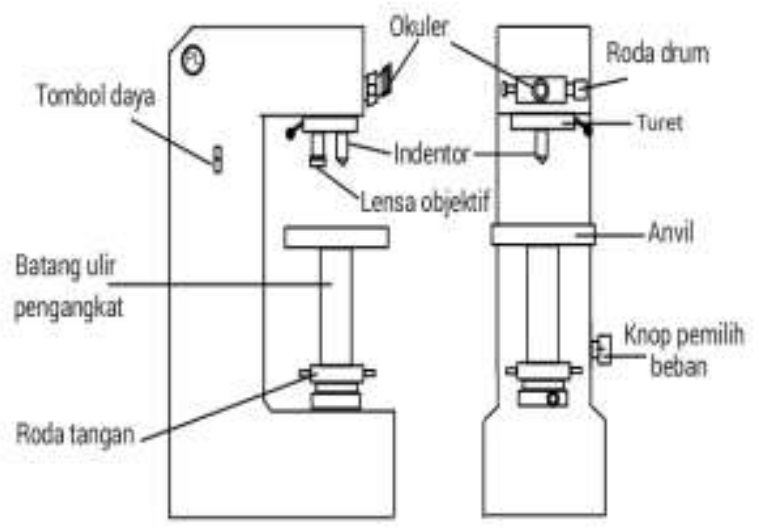

Gambar 2.6 Mesin Uji Vickers 


\section{METODOLOGI PENELITIAN Diagram Alir Penelitian}

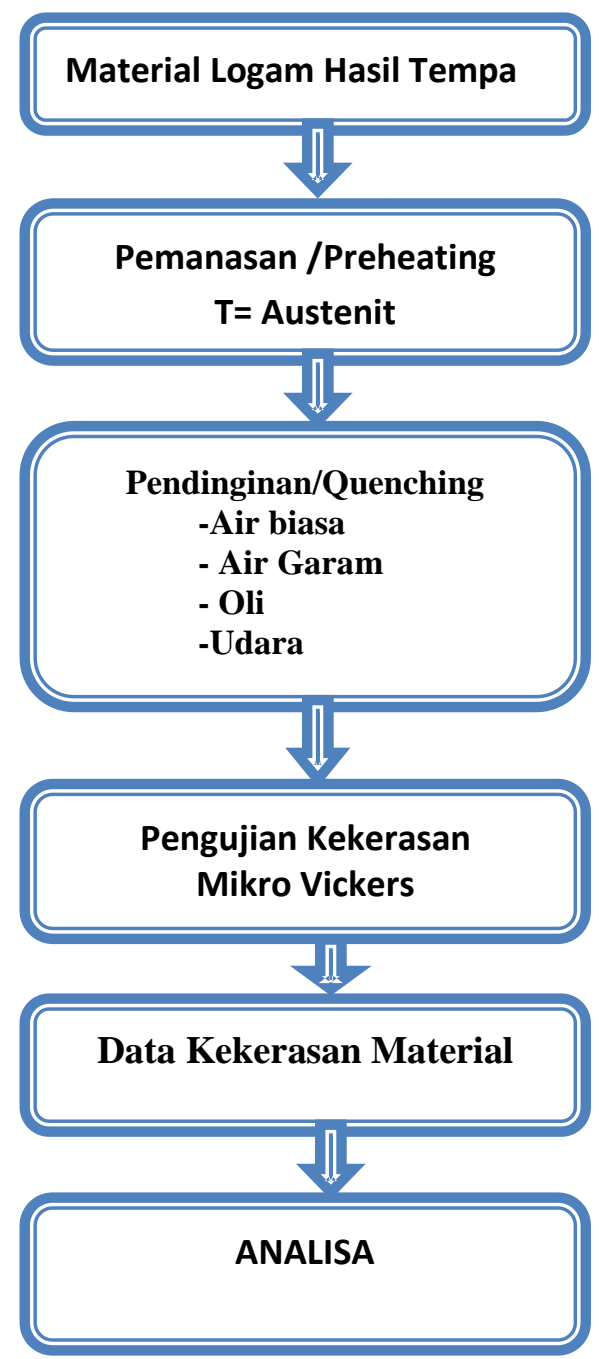

Gambar 3.1 Diagram Alir Penelitian

\section{DATA DAN ANALISA}

Data Hasil Uji Keras Mikro Vicker

Tabel 1 Data Kekerasan media Pendingin Air Biasa/Air sumur

\begin{tabular}{|c|c|}
\hline Material & VHN \\
\hline 1 & 660 \\
\hline 2 & 679 \\
\hline 3 & 659 \\
\hline $\mathbf{4}$ & $\mathbf{6 2 4}$ \\
\hline $\mathbf{5}$ & $\mathbf{6 4 1}$ \\
\hline Rata-rata & $\mathbf{6 5 2 . 6}$ \\
\hline
\end{tabular}

Tabel 2. Data Kekerasan Media Pendingin Air Garam

\begin{tabular}{|c|c|}
\hline Material & VHN \\
\hline \hline 1 & 840 \\
\hline 2 & 798 \\
\hline 3 & 891 \\
\hline 4 & 863 \\
\hline 5 & 956.3 \\
\hline Rata-rata & 869.66 \\
\hline
\end{tabular}

Tabel 3. Data Kekerasan Media Pendingin Oli

\begin{tabular}{|c|c|}
\hline \hline Material & VHN \\
\hline \hline 1 & 551.3 \\
\hline 2 & 647.6 \\
\hline 3 & 549.7 \\
\hline 4 & 648 \\
\hline 5 & 631 \\
\hline Rata-rata & 605.52 \\
\hline
\end{tabular}

Tabel 4. Data Kekerasan Media Pendingin Udara

\begin{tabular}{|c|c|}
\hline Material & VHN \\
\hline 1 & 342 \\
\hline 2 & 337.2 \\
\hline 3 & 332.9 \\
\hline 4 & 351.6 \\
\hline 5 & 328 \\
\hline Rata-rata & 338.34 \\
\hline
\end{tabular}

Tabel 5. Data Kekerasan Rata-rata dalam Media Pendingin yang bervariasi

\begin{tabular}{|c|c|}
\hline Material & VHN \\
\hline \hline Air & 652.6 \\
\hline Air Garam & 869.66 \\
\hline Oli & 605.52 \\
\hline Udara & 338.34 \\
\hline
\end{tabular}

Analisa

Proses perlakuan panas merupakan salah satu cara untuk meningkatkan kekerasan material baja karbon sedang hasil proses tempa. Material hasil proses pengerjaan panas atau material hasil proses deformasi plastis dipanaskan kembali sampai temperatur austenite kemudian temperatur ditahan sesuai dengan kadar karbon dan didinginkan secara cepat.

Selain pengaturan temperatur pemanasan dan penahanan temperatur, media pendingin sangat menentukan pada kekerasan material yang didapat. Dari data dapat dilihat 
bahwa media air garam yang paling tinggi menghasilkan kekerasan. Kekerasan diperoleh 869 VHN, sedangkan dalam oli dan air sumur hampir sama. Artinya media pendingin sangat menentukan dalam menghasilkan peningkatan kekerasan. Adapun yang menyebabkan perbedaan ini dapat dilihat dari viskositas/kekentalan dan densitas (masa jenis) media pendingin. Viskositas merupakan tingkat kekentalan yang dimiliki oleh fluida, semakin tinggi nilainya maka pendinginan akan semakin lambat karena proses penguapan akan lambat, terlihat dari media oli, angka kekerasan yang dihasilkkan lebih rendah dari pada media pendingin air sumur. Sedangkan densitas berbanding terbalik dengan viskositas, semakin tinggi densitas media pendingin maka laju pendinginan logam akan semakin cepat.

Menurut steeter dalam buku Fluid Machanic, 1992, dimana:

- Air Garam $\left(\rho=1025 \mathrm{~kg} / \mathrm{m}^{3}, v=1.01\right.$ Pa.s $)$ Air garam memiliki viskositas yang rendah dengan densitas yang tinggi sehingga kecepatan pendinginan lebih cepat dibanding media pendingin lainnya.

- Air Sumur/Air Tawar $\left(\rho=998 \mathrm{~kg} / \mathrm{m}^{3}, \mathrm{v}=\right.$ 1.01 Pa.s). Memiliki densitas yang lebih rendah dari air garam, sehingga laju pendinginan lebih rendah dibanding air garam.

- Oli $\left(\rho=981 \mathrm{~kg} / \mathrm{m}^{3}, v=4.02\right.$ Pa.s $)$. Oli memiliki viskositas yang tinggi dan densitas yang tinggi juga sehingga laju pendinginan lambat.

- Udara $\left(\rho=1,2 \mathrm{~kg} / \mathrm{m}^{3}, \mathrm{v}=0.0000175\right.$ Pa.s). Angka viskositas dan densitas yang sangat kecil ini maka laju pendinginan logam sangat lambat.

Dari perbedaan media pendingin diatas angka kekerasan yang paling besar diperoleh dengan media pendingin air garam yaitu $869 \mathrm{VHN}$.

\section{SIMPULAN DAN SARAN \\ Simpulan}

- Secara turun temurun pengrajin pandai besi Sungai Puar hanya melakukan proses quenching hanya dengan air sumur atau air hujan. Dari data pengujian kekerasan diatas didapat angka kekerasan 652.6 VHN dengan menggunakan media pendingin air sumur, sedangkan dengan air garam 869,66 VHN. Sebuah perbedaan yang sangat signifikan, dengan hanya menambahkan garam dapur kedalam media pendingin.

- Penelitian ini akan sangat bermanfaat jika disosialisasikan kepada pengrajin pandai besi agar produk hasil olahan pegas daun menjadi peralatan pertanian dapat ditingkatkan mutunya dan dapat bersaing dengan produk China.

\section{Saran}

- Penelitian ini harus dilanjutkan, walaupun angka kekerasan dengan media pendingin air garam lebih tinggi dibanding dengan air sumur dan oli, akan tetapi tingkat kegetasan produk belum diuji lebih lanjut.

- Perlu dikaji perubahan struktur mikro material karena air garam merupakan zat yang mempunyai viskositas yang kecil dengan densitas yang tinggi, sehingga pendinginan lebih cepat. Kenaikan sifat kekerasan apakah diikuti dengan sifat lainnya yang bermanfaat untuk produk.

- Penelitian perlu ditambah dengan penelitian laju korosi sehingga kekerasan yang didapat setara dengan ketahanan korosi.

\section{DAFTAR PUSTAKA}

Avner. 1987. Introduction to Pysical Metallurgy, $2^{\text {nd }}$ ed. New York: Mc. Graw-Hill Book Company.

Armila, M. T. "DENTINGAN PALU TEMPA PENGARAJIN PANDAI BESI SUNGAI PUAR MULAI SUNYI." RANG TEKNIK JOURNAL 1.2 (2018).

Beumer. 1985 Ilmu Bahan Logam Jilid II. Jakarta: Bharata Karya Aksara

Dieter. 1996 Metalurgi Mekanik II, Jakarta: Erlangga

Smallman dan Bishop. 1999. Metalurgi Fisik Modern dan Rekayasa Material

Streeter.1992. Fluid Mechanics, McGraw Hill, New York

Suherman. 1998. Ilmu Logam III. Surabaya: Teknik Mesin ITS Surabaya.

Surdia, Tata. 1985. Teknik Pengecoran Logam. Jakarta: PT. Pardya Paramita 